\title{
Blood Glucose Regulation Using an Open-Loop Insulin Delivery System in Pancreatectomized Dogs Given Glucose Infusions
}

\author{
I. Portal Square Waves
}

\author{
A. M. Albisser, C. K. Botz, and B. S. Leibel \\ Department of Surgery and Division of Biomedical Research, Research Institute, Hospital for Sick Children, Toronto, Canada
}

\begin{abstract}
Summary. This study characterizes the glycaemic and insulin responses of a group of 5 anaesthetized dogs to a portal glucose infusion of $10 \mathrm{mg} / \mathrm{kg} / \mathrm{min}$ before and after pancreatectomy. Insulin was administered intraportally to the pancreatectomized dogs according to a simple preprogrammed waveform composed of a constant basal rate of $0.35 \pm 0.02 \mathrm{mU} / \mathrm{kg} / \mathrm{min}$ which was increased to $2.00 \mathrm{mU} / \mathrm{kg} / \mathrm{min}$ at the time of the 60 minute glucose challenge. When this square waveform was applied the glycaemic response was similar to that seen in the normal controls in the baseline and challenge periods. Blood glucose concentration differed significantly $(p<0.05)$ only from 20 to 100 minutes after the end of the challenge when it was higher by $20 \pm 1 \mathrm{mg} / \mathrm{dl}$. Insulin levels were not significantly different from controls. It may be concluded that normoglycaemia and normoinsulinaemia can be maintained by a simple constant rate of portal insulin delivery while the blood glucose response to a glucose infusion can be ostensibly normalized without hyperinsulinaemia simply by enhancing insulin delivery during the challenge. The feasibility of this approach implies that with further development of the preprogrammed waveforms and with a greater understanding of their characteristics portable insulin delivery systems may be realized which accomodate more physiological challenges. The portal route for insulin delivery may however be necessary if peripheral hyperinsulinism is inappropriate.
\end{abstract}

Key words: Blood glucose regulation and control, glucose infusion, continuous low dose portal insulin infusion, pancreatectomized dog, artificial beta cell, hyperinsulinaemia.
Studies using closed-loop insulin delivery systems as an artificial endocrine pancreas [1-11] are unphysiological. Usually they are limited in duration to one or two days, partly because of the restrictions imposed by size, but mainly because of the need for continuous blood withdrawal [12] for glucose sensing [13]. The excellent glycaemic normalization achieved by these devices is frequently associated with peripheral hyperinsulinaemia [4, 14-16]. Whether peripheral insulin administration is the cause and whether the subsequent effects are undesirable remain to be established.

Because of these and other limitations imposed by the closed-loop systems, several groups [17-21] have described preprogrammed insulin delivery mechanisms. These open-loop devices do not depend on a glucose sensor and hence can be made portable enabling ambulant patients to participate in studies lasting more than one or two days. Waveforms used included various diurnal combinations of a 'basal' insulin rate enhanced during the meal period either as one or more square waves [17-19] or in a pattern intended to reproduce the normal peripheral insulin profile [20]. However, all studies involved human subjects, insulin was delivered peripherally and the challenges were always meals. In addition to episodes of hypoglycaemia, variable and somewhat unpredictable fasting and post-prandial blood glucose levels were observed. Whether or not such open-loop systems can be programmed to provide to the diabetic subjects all the benefits of a closed-loop system and none of its disadvantages remains to be established. It is in the light of these problems that the choice must be made between simple or complicated waveforms and between peripheral or portal routes for insulin infusion. 


\section{Materials and Methods}

\section{Animals}

Non-obese male beagles, one to two years old, and weighing 10.5 $\pm 0.3 \mathrm{~kg}$ were fasted for $12 \mathrm{~h}$ prior to each experiment. General anaesthesia was induced with IV pentobarbitol (Nembutal Sodium Injection, Abbott Laboratories, N. Chicago, Ill., U. S. A.), $25 \mathrm{mg}$ / $\mathrm{kg}$ body weight. Anaesthesia was maintained throughout the experiment by a slow infusion $(27 \mathrm{mg} / \mathrm{h})$ of pentobarbitol through a 20 gauge catheter (Argyle Medicut, Aloe Medical, St. Louis, Mo. U.S. A.) placed in a saphenous vein. Dual lumen catheters (Abjad Industries, Mississauga, Ont., Canada) were placed in both external contralateral jugular veins for continuous blood withdrawal: clotting in the catheter was controlled by mixing whole blood with a heparin solution $(25 \mathrm{U} / \mathrm{ml}) 1 \mathrm{~mm}$ inside the tip of the catheter. Heparin does not enter the general circulation. One dual lumen catheter was used exclusively for continuous monitoring of whole blood glucose, while the other was used intermittently to withdraw blood samples for insulin determinations at $-40,-10,0,5,10$, $15,30,45,60,75,90,120,150$ and $180 \mathrm{~min}$, where zero time coincided with the start of the glucose challenge. The 5 and $10 \mathrm{~min}$ samples were not drawn in the diabetic dogs. Samples were collected over ice, centrifuged and the plasma frozen and stored at $-20^{\circ} \mathrm{C}$ prior to insulin assay.

At the start of each experiment, the abdomen was opened through a mid-line incision and a loop of small bowel, and subsequently the spleen, were delivered into the wound. A polyethylene catheter (PE50 Intramedic, Clay Adams, Parsippany, N. J., U.S. A.) was inserted into a mesenteric vein and kept patent with a $0.154 \mathrm{mmol} / 1$ saline infusion $(0.6 \mathrm{ml} / \mathrm{min})$. This portal route was always used for the glucose infusion and for the delivery of insulin in all the studies on diabetic animals. Insulin was delivered by a pulsatile pump (Lambda Pump, Harvard Instruments, Millis, Mass. U. S. A.). After the initial study on the healthy animal total pancreatectomy was performed as previously described [4].

Each dog was allowed a 4-6 week recovery period following pancreatectomy during which time it was maintained on a daily basis by subcutaneous injection of 12-20 Units of NPH porcine insulin (Connaught Laboratories Ltd., Toronto, Ont., Canada) and was fed the usual diet plus 12 capsules of an exocrine pancreatic supplement (Cotazyme, Organon Ltd., Montreal, Quebec, Canada).

On the day before experiments each dog was switched from a single to two SC injections of regular porcine crystalline zinc insulin given at 0900 and $2000 \mathrm{~h}$ in order to ensure that the release rate of insulin from the subcutaneous depot on the day of the experiment was minimal in comparison to the intravenously administered insulin. On the day of the experiment the fasting glucose level ranged from 300 to $400 \mathrm{mg} / \mathrm{dl}$ and was lowered to normoglycaemic values of 80 to $100 \mathrm{mg} / \mathrm{dl}$ before the baseline period by the combination of a continuous infusion of insulin with boluses of 0.5 to 1.0 Units as needed.

\section{Analytical Methods}

An AutoAnalyzer (Technicon Corp., Tarrytown, N. Y., U. S. A.) using a modified [13] glucose oxidase (GOD Perid, Boehringer Mannheim Corp., N. Y., U. S. A.) methodology was used to measure whole blood glucose continuously. Calibration of the method was performed against an independent glucose analyzer (Beckman Instruments, Fullerton, Cal., U.S. A.). Plasma immuno-reactive insulin (IRI) was determined using an assay kit employing porcine insulin standard (Phedebas Insulin Test, Pharmacia, AB, Uppsala, Sweden).
Regular crystalline zinc porcine insulin (Connaught Laboratories, Toronto, Ont., Canada) diluted in $0.154 \mathrm{mmol} / 1$ saline to a concentration of $50 \mathrm{U} / 1$ was used for infusion. The precision of this dilution was verified by immunoassay.

Pooled data populations were compared statistically using the unpaired Student $\mathrm{t}$ test.

\section{Experimental Design}

Glucose challenges consisted of a $60 \mathrm{~min}$ intraportal infusion at the rate of $10 \mathrm{mg} / \mathrm{kg} / \mathrm{min}$. All challenges started after a $40 \mathrm{~min}$ baseline period and were followed by a $120 \mathrm{~min}$ recovery period. During the baseline period, glycaemia was required to be not only stable but also in the normal range, the total change (upward or downward) being less than $10 \mathrm{mg} / \mathrm{dl}$.

Dogs were studied twice: once as healthy controls just prior to pancreatectomy and later as diabetics. To examine the reproducibility of this method one dog was given two consecutive glucose challenges from the same baseline conditions and another was repeatedly studied a total of 4 times. Because of the close similarity of the results, all the data was pooled.

In the diabetics exogenous intraportal insulin was administered by an open-loop system preprogrammed to deliver insulin according to a fixed waveform. This waveform consisted of two rates of insulin delivery: a constant low (basal) rate of $0.35 \pm 0.02 \mathrm{mU} / \mathrm{kg} /$ min delivered during the baseline and recovery periods and an augmented rate of $2.00 \mathrm{mU} / \mathrm{kg} / \mathrm{min}$ coincident in time with the glucose challenge. For each dog the 'basal' rate was determined by the requirements of the baseline period described above while the elevated rate was fixed, on the basis of previously published results [4]. Those studies with a closed-loop insulin delivery system showed that an almost constant rate of some $2 \mathrm{mU} / \mathrm{kg} / \mathrm{min}$ administered over the last 20 to $30 \mathrm{~min}$ of a $60 \mathrm{~min}$ glucose infusion was sufficient to restore a normal glycaemic response in pancreatectomized dogs. The early phase of rate-dependent extrainsulin administered by their artificial endocrine pancreas was not incorporated into the square-wave of the present work because of the absence in this study of the $4 \frac{1}{2} / 2$ min delay that Botz et al. [4] experienced with their system.

\section{Results}

\section{Normal Controls}

The responses of the healthy dogs to intraportal glucose challenges are shown in Figure 1. Figure 1a depicts the plasma glucose concentrations selected at $10 \mathrm{~min}$ intervals from the continuous record before, during and after the standardized glucose challenge. The plasma glucose concentration in the baseline period was $89 \pm 2 \mathrm{mg} / \mathrm{dl}$ and rose rapidly with the challenge approaching a plateau between 150 and $160 \mathrm{mg} / \mathrm{dl}$ at the end of the infusion. Upon termination of the challenge the glucose concentration fell to normal levels $(<100 \mathrm{mg} / \mathrm{dl})$ within 30 minutes remaining at prechallenge levels for the following 90 minutes.

Peripheral IRI levels shown in Fig. $1 \mathrm{~b}$ were $17 \pm$ $6 \mu \mathrm{U} / \mathrm{ml}$ in the baseline period rising rapidly with the challenge to levels of $35 \pm 5 \mu \mathrm{U} / \mathrm{ml}$ and declining 


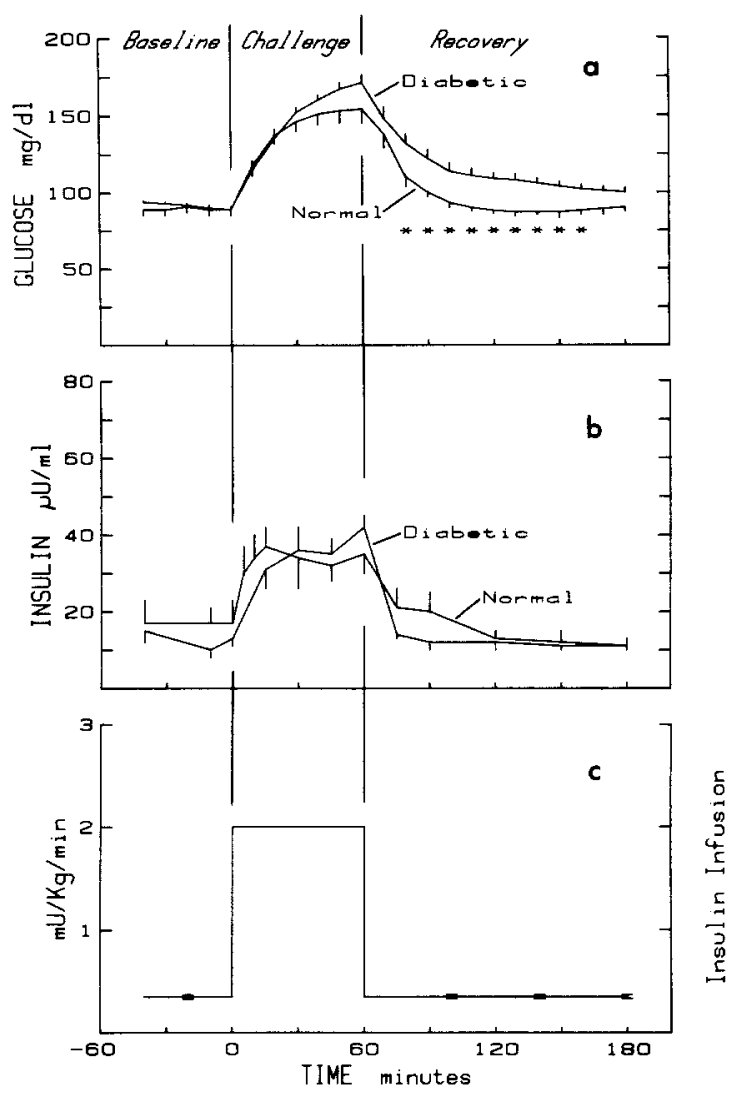

Fig. 1a-c. Mean \pm SEM of the responses of 5 dogs to a portal glucose infusion of $10 \mathrm{mg} / \mathrm{kg} / \mathrm{min}$ for 60 minutes. a Peripheral glucose concentration in normal $(n=5)$ and diabetic $(n=10)$ dogs. Asterisks denote significant differences $(p<0.05)$ between groups. b Peripheral insulin levels. c Portal insulin infusion rates, diabetics only $(n=10)$

gradually following the end of the glucose infusion to prechallenge levels some 60 minutes later.

\section{Insulin Delivery by the Open-Loop System: Diabetic Dogs}

Figure 1 also summarizes the responses of the dogs after pancreatectomy to an intraportal glucose challenge when the predetermined simple waveform of insulin shown in Fig. $1 \mathrm{c}$ was administered by the open-loop system. During the 40 minute baseline period the blood glucose level (Fig. 1a) declined from $94 \pm 1$ to $89 \pm 2 \mathrm{mg} / \mathrm{dl}$, but rose rapidly with the glucose infusion to $171 \pm 5 \mathrm{mg} / \mathrm{dl}$ without approaching a plateau at the end of the challenge, thereafter falling gradually to approach the baseline value in 2 hours. Blood glucose levels were not significantly different from controls in the baseline and challenge periods but were significantly higher by 20 $\pm 1 \mathrm{mg} / \mathrm{dl}$ between 80 and 160 minutes in the recovery period $(p<0.05)$.
During the baseline period the peripheral IRI levels (Fig. $1 \mathrm{~b}$ ) were $13 \pm 3 \mu \mathrm{U} / \mathrm{ml}$ and rose during the challenge concurrent with the increased insulin infusion to a peak at the end of the challenge of $42 \pm$ $3 \mu \mathrm{U} / \mathrm{ml}$ thereafter declining rapidly to baseline values. For the group of diabetic animals the predetermined insulin infusion pattern included a basal constant rate in the baseline and recovery periods of 0.35 $\pm 0.02 \mathrm{mU} / \mathrm{kg} / \mathrm{min}$ which was increased to $2.00 \mathrm{mU} /$ $\mathrm{kg} / \mathrm{min}$ during the glucose infusion (Fig. 1c).

\section{Discussion}

The simplest form of an open-loop insulin delivery system would be one that administered insulin at that constant rate which maintains normoglycaemia in the fasting or postabsorptive states. Such a 'basal' rate would not however be sufficient to normalise the glycaemic excursion during caloric challenge [15]. Thus the next to simplest form of an open-loop system would include an augmented rate of insulin delivery which coincided with food intake. In the work presented here, this latter insulin delivery waveform was chosen and constrained in two respects based on the results obtained from the previous application of a closed-loop insulin delivery system [4]. While the first constraint imposed equal basal rates both in the baseline and recovery periods, the second limited the rate of insulin delivery during glucose challenge to a constant value of $2.00 \mathrm{mU} / \mathrm{kg} / \mathrm{min}$.

The results of this study imply that the glycaemic response of the diabetic differs in only one respect from that of the normal dog. With the simple portal square wave of insulin infusion used in this study the open-loop system did not curb the rising glycaemia so that the usual plateau seen in normal animals was not established by the end of the glucose infusion. Thus following the end of the challenge, the blood glucose level in the recovery period was some $20 \mathrm{mg} / \mathrm{dl}$ higher with the open-loop system than that observed in the normal controls. However, normal peripheral insulin levels were obtained.

Comparing the levels of IRI achieved in the periphery it appears as if the rise with the open-loop system was slower than normal although the levels were not significantly different. It may well be only a lack of sufficient early (biphasic) insulin delivery with this simple open-loop waveform that results in the mildly unattenuated glycaemia toward the end of the glucose challenge. Clearly following the challenge the fall in peripheral IRI was more rapid than in the normal controls and reflects the abrupt downward shift in the rate of insulin delivery with the open-loop system. This work has not established (i) whether 
these differences can be resolved by altering the shape of the insulin delivery waveform to include more total insulin or more early insulin by the addition of a larger priming component and perhaps a more gradual decline at the end of the challenge and (ii) whether these alterations can be achieved without producing hypoglycaemia in the recovery period.

For the group the basal insulin infusion rate of $0.35 \pm 0.02 \mathrm{mU} / \mathrm{kg} / \mathrm{min}$ appears slightly excessive and resulted in the slowly declining blood glucose in the baseline period (Fig. 1a). However, this basal rate does not lead to eventual hypoglycaemia in the absence of a challenge but rather leads to a slightly lower fasting level of blood glucose than the $89 \mathrm{mg} / \mathrm{dl}$ observed at time 0 (results not presented). It agrees with the basal rates used by others [22, 23].

This work has demonstrated that a preprogrammed combination of two rates of portal insulin delivery in a simple square-wave pattern restores to pancreatectomized dogs a glycaemic response to an intraportal glucose infusion which compares favorably with that obtained in normal controls. The unphysiological peripheral insulinaemia that is reported to occur with the application of the closedloop insulin delivery system $[4,14-16]$ is not observed in these studies. The present findings suggest that it is more the portal (natural) route than the rate and the waveform of insulin delivery that results in normal peripheral insulin levels.

The 60 minute glucose infusion at a rate of $10 \mathrm{mg} / \mathrm{kg} / \mathrm{min}$ into the portal vein was chosen because it is a defined caloric challenge which results in reproducible glucose and insulin responses in the dog [4]. At the same time it avoids the important physiological variations of gastrointestinal absorption and the gut factors which undoubtedly would affect the response if glucose were administered intraduodenally or taken orally. This intravenous glucose infusion is a strong stimulus to the glucoregulatory system. In pancreatectomized dogs it produces a glycaemic response which perviously could only be normalized by a closed-loop insulin delivery system specifically programmed to meet this challenge $[24,4]$. In the present study, repeated challenges under identical experimental conditions, either on the same day or weeks later, verified the reproducibility of the response of each dog (individual data not shown).

Previously we were successful in translating results from the glucose infused pancreatectomized animal [24] to the calorically challenged human diabetic [25]. We are now confident that with further development of the waveforms and a greater understanding of the significance of the routes of insulin infusion portable open-loop systems will be evolved which will approximate the function of the more complicated closed-loop system.

The major advantage of the open-loop system is its simplicity, applicability and the absent need for a glucose sensor. Prototype open-loop insulin delivery systems [26] are proving useful in the early realization of portable blood glucose control devices for further animal [15] and human studies.

Acknowledgements. This work was conducted as a research project in the Artificial Pancreas Programme at The Hospital for Sick Children in Toronto, and benefited in part from the financial support of The Juvenile Diabetes Foundation, The Juvenile Diabetes Research Foundation, The Medical Research Council of Canada, The Pfizer Company of Canada and an Ontario Ministry of Health Fellowship to one of the authors (CKB) who gratefully acknowledges the advice, supervision and help given to him by Dr. W. Zingg, Director, and the staff of the Division of Surgical Research, Department of Surgery at The Hospital for Sick Children.

\section{References}

1. Albisser, A. M., Leibel, B. S.: The artificial pancreas. Clin. Endocrinol. Metabol. 6, 457-479 (1977)

2. Albisser, A.M., Leibel, B.S., Zinman, B., Murray, F.T., Zingg, W., Botz, C. K., Denoga, A., Marliss, E. B.: Studies with an artificial endocrine pancreas. Arch. Intern. Med. 137, 639-649 (1977)

3. Botz, C. K.: An improved control algorithm for an artificial beta cell. Biomed. Eng. 23, 252-255 (1976)

4. Botz, C. K., Albisser, A. M., Leibel, B. S., Zingg, W., Gander, R. E.: Comparison of peripheral and portal routes of insulin infusion by a computer-controlled insulin infusion system (artificial endocrine pancreas). Diabetes 25, 691-700 (1976)

5. Pfeiffer, E. F., Clemens, A. H.: The artificial beta cell - a continuous control of blood sugar by external regulation of insulin infusion (glucose controlled insulin infusion system). Horm. Metab. Res. 487, 339-342 (1974)

6. Kraegen, E.W., Campbell, L.V., Chia, Y.O., Meler, H., Lazarus, L.: Control of blood glucose in diabetics using an artificial pancreas. Aust. N. Z. J. Med. 7, 280-286 (1977)

7. Kawamori, R., Shichiri, M., Goriya, Y., Yamasaki, Y., Shigeta, Y., Abe, H.: Importance of insulin secretion based on the rate of change in blood glucose concentration in glucose tolerance, assessed by the artificial beta cell. Acta Endocrinol. (Kbh.) 87, 339-351 (1977)

8. Fischer, U., Freyse, E.-J., Salzsieder, E., Jutzi, E., Albrecht, G.: Glukose-abhängig gesteuerte Insulininfusion bei der Stoffwechselführung diabetischer Hunde. 9th Karlsburger Symposium über Diabetesfragen, pp. 156-160, Karlsburg 1977

9. Marliss, E. B., Murray, F. T., Stokes, E. F., Zinman, B., Nakhooda, A. F., Denoga, A., Leibel, B. S., Albisser, A. M.: Normalization of glycemia in diabetics during meals with insulin and glucagon delivery by the artificial pancreas. Diabetes 26, 663-672 (1977)

10. Mirouze, J., Selam, J. L., Pham, T. C., Orsetti, A.: Le pancréas artificiel extracorporel: nouvelle orientation du traitement insulinique. XIV Cong. Intern, de Thérapeut., pp. 79-91. Paris: L'Expansion Scientifique Française 1977

11. Kudlow, J., Albisser, A. M., Angel, A., Langer, B., Yip, C., Zinman, B., Stokes, E.: Insulinoma resection facilitated by the artificial endocrine pancreas. Diabetes 27, 774-777 (1978) 
12. Gander, R. E., Albisser, A. M., Botz, C. K., Leibel, B. S., Zingg, W.: An all plastic double-lumen catheter for continuous blood sampling. J. A. A. M. I. 9, 187-188 (1975)

13. Albisser, A. M., Leibel, B. S., Johnson, W., Denoga, A., Botz, C. K., Marliss, E. B.: An improved technique for the rapid continuous measurement of whole blood glucose, suitable for clinical application in an artificial endocrine pancreas. Med. Prog. Technol. 5, 141-148 (1977)

14. Horwitz, D. L., Gonen, B., Zeidler, A., Langer, B., Rodman, D.: An "artificial beta cell" for control of diabetes: comparison of glucose and free insulin levels with those achieved by subcutaneous insulin. Diabetes 26 (Suppl. 1), 376 (1977)

15. Albisser, A. M., Bahoric, A., Goriya, Y., Jackman, W. S., Ferguson, T., Leibel, B.S.: Control of experimental diabetes using a portable insulin delivery system. Diabetes 27 (Suppl. 1), 439 (1978)

16. Zinman, B., Stokes, E. F., Nakhooda, A. F., Leibel, B.S., Marliss, E. B.: The metabolic response to glycemic control by the artificial endocrine pancreas (AEP) in diabetic man. Diabetes 27 (Suppl. 1), 431 (1978)

17. Slama, G., Hautecouverture, M., Assan, R., Tchobroutsky, G.: One to five days of continuous intravenous insulin infusion on seven diabetic patients. Diabetes 23, 732-738 (1974)

18. Service, J. F.: Normalization of plasma glucose of unstable diabetes: studies under ambulatory, fed conditions with pumped intravenous insulin. J. Lab. Clin. Med. 91, 480-489 (1978)

19. Deckert, T., Lørup, B.: Regulation of brittle diabetics by a pre-planned insulin infusion programme. Diabetologia 12, 573-579 (1976)

20. Genuth, S., Martin, P.: Control of hyperglycaemia in adult diabetics by pulsed insulin delivery. Diabetes 26, 571-581 (1977)
21. Pickup, J. C., Keen, H., Parsons, J. A., Alberti, K. G. M. M.: Continuous subcutaneous insulin infusion: an approach to achieving normoglycaemia. Br. Med. J. 1978 I, 204-207

22. Cherrington, A.D., Chiasson, J. L., Liljenquist, J. E., Jennings, A. S., Keller, U., Lacy, W. W.: The role of insulin and glucagon in the regulation of basal glucose production in the postabsorptive dog. J. Clin. Invest. 58, 1407-1418 (1976)

23. Cherrington, A. D., Vranic, M.: Effect of interaction between insulin and glucagon on glucose turnover and FFA concentration in normal and depancreatized dogs. Metabolism 23, 729-744 (1974)

24. Albisser, A. M., Leibel, B. S., Ewart, T. G., Davidovac, Z., Botz, C. K., Zingg, W.: An artificial endocrine pancreas. Diabetes 23, 389-396 (1974)

25. Albisser, A. M., Leibel, B. S., Ewart, T. G., Davidovac, Z., Botz, C. K., Zingg, W., Schipper, H., Gander, R.: Clinical control of diabetes by the artificial pancreas. Diabetes 23, 397-404 (1974)

26. Albisser, A. M., Jackman, W. S., Ferguson, R., Bahoric, A., Goriya, Y.: A portable precision pumping system for chronic, programmed insulin infusion. Med. Prog. Technol. 5, 187-193 (1978)

Received: July 10, 1978, and in revised form: October 4, 1978

Dr. A. M. Albisser

Division of Biomedical Research

The Hospital for Sick Children

555 University Avenue

Toronto, Ontario

Canada M5G 1X8 